\title{
Período de estacionalidade de produção de pastagens irrigadas
}

\author{
Joaquim Bartolomeu Rassini ${ }^{(1)}$ \\ (1)Embrapa Pecuária Sudeste, Caixa Postal 339, CEP 13560-970 São Carlos, SP. E-mail: rassini@cppse.embrapa.br
}

\begin{abstract}
Resumo - O objetivo deste trabalho foi caracterizar o período de estacionalidade de produção de matéria seca de espécies forrageiras irrigadas. As espécies utilizadas foram Pennisetum purpureum cv. Taiwan (capim-elefante), Panicum maximum cv. Tanzânia (capim-tanzânia), Brachiaria decumbens cv. Basilisk (capim-braquiária), Brachiaria bryzantha cv. Marandu (capim-marandu), Paspalum atratum cv. Pojuca (capim-pojuca) e Cynodon dactylon cv. Coastcross (capim-coastcross). Durante dois anos (1999/2000 e 2000/2001), avaliaram-se as condições climáticas do local onde o experimento foi realizado e as características fenológicas das forrageiras. As pastagens irrigadas têm um período de 65 a 70 dias de estacionalidade de produção durante o ano, em que, mesmo satisfazendo as necessidades hídricas da planta forrageira, não há produção de matéria seca.
\end{abstract}

Termos para indexação: condições climáticas, fenologia, forragem, matéria seca.

\section{Seasonality period of production in irrigated pastures}

\begin{abstract}
This study was conducted to evaluate the seasonal period of dry matter production of irrigated forages species: Elephantgrass (Pennisetum purpureum), Guineagrass cv. Tanzania (Panicum maximum), Signalgrass (Brachiaria decumbens), Tannergrass (Brachiaria bryzantha), Pojucagrass (Paspalum atratum) and Bermudagrass cv. Coastcross (Cynodon dactylon). Climatic conditions and forages cycles were evaluated during two years (1999/2000 and 2000/2001). The seasonal production of irrigated pastures is of 65 to 70 days in the year. In such seasonal period there is no dry matter production even when hydric requirements of grasses are met through irrigation.
\end{abstract}

Index terms: climatic conditions, forage cycle, forages, dry matter.

\section{Introdução}

No Sudeste do Brasil, os primeiros trabalhos sobre irrigação de pastagens demonstraram que essa técnica, apesar de aumentar a produção total de matéria seca no ano, não contribuía para alterar a curva de estacionalidade de produção. Guelfi Filho (1972), com irrigação em capim-elefante, obteve 18,7, 18,4 e 18,2 t ha-1 de matéria seca (MS) no verão e 5,9, 6,0 e 5,7 t ha-1 de MS no inverno, resultando em uma relação inverno/verão de 31,33 e $31 \%$. Com o Panicum maximum cv. Colonião (capim-colonião), a irrigação também proporcionou aumentos na produção de matéria seca durante o ano, sem entretanto alterar a estacionalidade de produção (Guelfi Filho, 1978). Faria \& Corsi (1986), com $75 \%$ de água disponível no solo, verificaram que o capimelefante produziu $72 \%$ no verão e $28 \%$ no inverno.
A partir da década de 80 , os trabalhos com irrigação em pastagens passaram a comparar as produções de entressafra (outono-inverno) com as da safra (primavera-verão), mudando os valores e números em relação a essa técnica. Alvim et al. (1986), em Coronel Pacheco, MG, com 11 espécies forrageiras irrigadas, obtiveram produção média de entressafra de 30\% da anual, ou seja, 5,6 e 18,3 tha-1 de MS, respectivamente. Entretanto, quando relacionaram essa produção com a da safra, o porcentual foi de 44\% (5,6 e 12,7 t ha ${ }^{-1}$ de MS). Em Uberlândia, MG, Benedetti et al. (2000) concluíram que o acúmulo de forragem do capim-tanzânia irrigado na entressafra correspondia a $57 \%$ do acúmulo na safra.

Penati et al. (2001) em Piracicaba, SP, com irrigação do capim-tanzânia, verificaram que a taxa de lotação animal manteve-se constante e ao redor de 5 UA por ha, 
não diferindo do pastejo rotativo de sequeiro. Esse índice, segundo os autores, ocorreu em razão das perdas elevadas de forragem, durante a estabilização da pastagem no início da experimentação.

O objetivo deste trabalho foi caracterizar o período de estacionalidade de produção de matéria seca de seis espécies forrageiras irrigadas.

\section{Material e Métodos}

O trabalho foi realizado entre novembro/1999 e novembro/2001 na Embrapa Pecuária Sudeste, São Carlos, SP, num Latossolo Vermelho-Amarelo de textura média e relevo plano, com as seguintes características físico-químicas na camada de 0 a $20 \mathrm{~cm}$ : argila, $279 \mathrm{~g} \mathrm{~kg}^{-1}$; macroporos, 15\%; condutividade hidráulica, 3,8 $\mathrm{m} \mathrm{dia}^{-1}$; taxa de infiltração, $273 \mathrm{~mm}_{\text {hora }}{ }^{-1}$; capacidade de

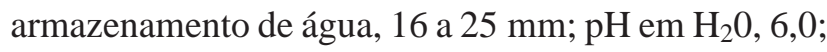
$\mathrm{pH}$ em $\mathrm{CaCl}_{2}, 5,2$; matéria orgânica, $25 \mathrm{~g} \mathrm{dm}^{-3}$; $\mathrm{P}$, $13 \mathrm{mg} \mathrm{dm}^{-3} ; \mathrm{K}, 1,3 \mathrm{mmol} \mathrm{dm}^{-3} ; \mathrm{Ca}, 40 \mathrm{mmol} \mathrm{dm}^{-3} ; \mathrm{Mg}$, $14 \mathrm{mmol} \mathrm{dm}^{-3} ; \mathrm{Al}, 1 \mathrm{mmol} \mathrm{dm}^{-3}$; capacidade de troca de cátions, $80 \mathrm{mmol} \mathrm{dm}^{-3}$; e saturação de bases, $57 \%$.

O preparo do solo consistiu de uma aração e duas gradagens. Foram aplicadas $2 \mathrm{t} \mathrm{ha}^{-1}$ de calcário dolomítico, $170 \mathrm{~kg} \mathrm{ha}^{-1}$ de $\mathrm{K}_{2} \mathrm{O}$ (cloreto de potássio) e $30 \mathrm{~kg} \mathrm{ha}^{-1}$ de FTE BR-12. No segundo ano (dezembro/ 2000), aplicaram-se $5 \mathrm{t} \mathrm{ha}^{-1}$ de calcário dolomítico, $130 \mathrm{~kg} \mathrm{ha}^{-1}$ de $\mathrm{P}_{2} \mathrm{O}_{5}$ (superfosfato simples) e $165 \mathrm{~kg} \mathrm{ha}^{-1}$ de $\mathrm{K}_{2} \mathrm{O}$ (cloreto de potássio). Após os cortes, sendo o primeiro de uniformização em 8/2/2000, e os de avaliação de produção, aplicaram-se a lanço, $40 \mathrm{~kg} \mathrm{ha}^{-1}$ de N (sulfato de amônio).

As seis forrageiras foram estabelecidas no dia 25/11/1999, e o manejo, quanto à altura de corte e resíduo, foi realizado conforme Corsi (1995) (capimtanzânia), Zimmer et al. (1995) (capim-braquiária e capim-marandu), Maraschin (1995) (capim-coastcross), Hillesheim (1995) (capim-elefante) e Kalmbacher et al. (1997) (capim-pojuca).

A irrigação foi realizada por quatro aspersores de giro completo, monitorada por dados climáticos coletados na estação meteorológica da Embrapa Pecuária Sudeste, bem como por seis pluviômetros e um tanque Classe A instalados na área experimental. O manejo da água foi baseado na evaporação do tanque Classe A e na precipitação pluvial, conforme Rassini (2002) para latossolos de textura média. No primeiro ano foram re- alizadas 21 irrigações, aplicando-se em média $316 \mathrm{~mm}$ com lâminas de 15,7 mm e, no segundo ano, 24 irrigações, aplicando-se $481 \mathrm{~mm}$ com lâminas de $20,0 \mathrm{~mm}$.

O delineamento experimental foi o de blocos casualizados dispostos em esquema de faixas, com as parcelas principais compostas pelas duas condições hídricas (irrigado e não irrigado), e as subparcelas pelas seis espécies forrageiras, com três repetições. A área de cada parcela era de $10 \mathrm{~m}^{2}$. O rendimento de forragem, obtido por cortes manuais, foi analisado pelo procedimento GLM do SAS (SAS Institute, 1993), e as médias comparadas pelo teste de Tukey a $5 \%$ de probabilidade. Os dados de fenologia das espécies forrageiras, como ciclo para cortes (dias) e estádio reprodutivo, foram obtidos mediante observações diárias das plantas, confrontando-os com as descrições morfológicas de rendimento, como altura da planta para a produção e de corte para resíduo.

\section{Resultados e Discussão}

No período experimental, a distribuição estacional da temperatura, umidade relativa e precipitação pluvial, evidenciou que na região ocorrem duas épocas bem definidas: águas e secas (Tabela 1).

Entretanto, no segundo ano agrícola (2000/2001), ocorreu uma redução de $20 \%$ a 30\% nas precipitações pluviais, em relação às normais climatológicas da série 19611990, que expressam um regime pluviométrico de $1.495 \mathrm{~mm}$ anuais para a região de acordo com Brasil (1992). Apesar de as chuvas serem suficientes para qualquer cultivo econômico, a precipitação pluvial é bastante variável, concentrando-se entre os meses de dezembro a março, de acordo com dados de Primavesi et al. (1999).

Em virtude dessas condições climáticas, foi analisado o comportamento fenológico das espécies forrageiras, em duas condições hídricas: irrigado e não irrigado (Tabela 2). Verificou-se que o período de formação em relação ao primeiro corte das espécies forrageiras foi de 74 dias. Após essa fase de estabelecimento e em condições irrigadas, realizaram-se sete cortes no primeiro ano, e nove no segundo. Nas condições sem irrigação, realizaram-se quatro e seis cortes, respectivamente, no primeiro e segundo ano. A média entre esses cortes, sem considerar os períodos de estacionalidade de produção, foi de 35 a 40 dias, corroborando dados obtidos por outros autores (Peixoto et al., 1995). 
A produção durante a entressafra foi bastante influenciada pelas condições climáticas, quando não houve irrigação. Com o déficit hídrico do segundo ano agrícola (2000/2001), o período de entressafra foi de 186 dias. Porém, no primeiro ano agrícola (1999/2000), quando as condições climáticas foram mais semelhantes ao regime hídrico regional, esse período foi de 155 dias. Rolim (1994), mediante levantamento de trabalhos com irriga- ção em pastagens na região Sudeste, também verificou que a estacionalidade de produção das espécies forrageiras tropicais em condições de sequeiro na entressafra é de 150 dias. Por sua vez, com a irrigação, esse período foi mais semelhante nos dois anos, independentemente das condições climáticas, ou seja, de 70 e 66 dias, respectivamente, em 1999/2000 e 2000/2001 (Tabela 2).

Tabela 1. Dados meteorológicos de três anos, do Município de São Carlos, $\mathrm{SP}^{(1)}$.

\begin{tabular}{|c|c|c|c|c|c|c|c|c|c|c|c|c|}
\hline \multirow[t]{2}{*}{ Mês } & \multicolumn{4}{|c|}{1999} & \multicolumn{4}{|c|}{2000} & \multicolumn{4}{|c|}{2001} \\
\hline & $\begin{array}{c}\text { Tmax } \\
\left({ }^{\circ} \mathrm{C}\right)\end{array}$ & $\begin{array}{l}\text { Tmin } \\
\left({ }^{\circ} \mathrm{C}\right)\end{array}$ & $\begin{array}{l}\mathrm{UR} \\
(\%)\end{array}$ & $\begin{array}{c}\text { Precipitação } \\
(\mathrm{mm})\end{array}$ & $\begin{array}{c}\text { Tmax } \\
\left({ }^{\circ} \mathrm{C}\right)\end{array}$ & $\begin{array}{l}\text { Tmin } \\
\left({ }^{\circ} \mathrm{C}\right)\end{array}$ & $\begin{array}{l}\mathrm{UR} \\
(\%)\end{array}$ & $\begin{array}{c}\text { Precipitação } \\
(\mathrm{mm})\end{array}$ & $\begin{array}{c}\text { Tmax } \\
\left({ }^{\circ} \mathrm{C}\right)\end{array}$ & $\begin{array}{l}\text { Tmin } \\
\left({ }^{\circ} \mathrm{C}\right)\end{array}$ & $\begin{array}{l}\mathrm{UR} \\
(\%)\end{array}$ & $\begin{array}{c}\text { Precipitação } \\
(\mathrm{mm})\end{array}$ \\
\hline Janeiro & 28 & 19 & 86 & 490 & 29 & 18 & 78 & 278 & 29 & 18 & 82 & 150 \\
\hline Fevereiro & 30 & 19 & 81 & 259 & 28 & 19 & 88 & 337 & 30 & 20 & 81 & 104 \\
\hline Março & 29 & 18 & 78 & 116 & 28 & 18 & 84 & 175 & 30 & 19 & 86 & 151 \\
\hline Abril & 27 & 16 & 75 & 96 & 28 & 16 & 66 & 6 & 29 & 17 & 77 & 26 \\
\hline Maio & 24 & 12 & 71 & 18 & 25 & 13 & 67 & 18 & 26 & 14 & 89 & 71 \\
\hline Junho & 24 & 12 & 80 & 54 & 26 & 13 & 74 & 1 & 24 & 13 & 81 & 11 \\
\hline Julho & 25 & 13 & 72 & 6 & 24 & 10 & 75 & 40 & 26 & 18 & 71 & 6 \\
\hline Agosto & 27 & 12 & 62 & 0 & 26 & 13 & 78 & 41 & 27 & 13 & 64 & 35 \\
\hline Setembro & 27 & 14 & 61 & 99 & 26 & 15 & 82 & 155 & 27 & 16 & 59 & 82 \\
\hline Outubro & 27 & 15 & 74 & 45 & 31 & 18 & 77 & 86 & 28 & 16 & 69 & 108 \\
\hline Novembro & 28 & 15 & 73 & 77 & 28 & 18 & 84 & 204 & 28 & 18 & 92 & 183 \\
\hline Dezembro & 28 & 18 & 87 & 287 & 28 & 18 & 86 & 220 & 27 & 18 & 92 & 275 \\
\hline Média anual & 27 & 15 & 75 & 1.547 & 27 & 16 & 78 & 1.561 & 28 & 17 & 79 & 1.202 \\
\hline
\end{tabular}

(1)Tmax: temperatura máxima; Tmin: temperatura mínima; UR: umidade relativa.

Tabela 2. Ciclo de seis espécies forrageiras, com e sem irrigação, no Município de São Carlos, SP.

\begin{tabular}{|c|c|c|c|c|c|c|}
\hline \multirow[t]{2}{*}{ Corte } & \multicolumn{3}{|c|}{ Irrigado } & \multicolumn{3}{|c|}{ Não irrigado } \\
\hline & Período (datas) & $\operatorname{PRP}^{(1)}(\mathrm{mm})$ & Ciclo (dias) & Período (datas) & $\mathrm{PRP}(\mathrm{mm})$ & Ciclo (dias) \\
\hline & \multicolumn{6}{|c|}{$1999 / 2000$} \\
\hline $\mathrm{U}^{(2)}$ & $25 / 11-08 / 02$ & 699 & 74 & $25 / 11-08 / 02$ & 699 & 74 \\
\hline 1 & 08/02-16/03 & 452 & 37 & $08 / 02-16 / 03$ & 452 & 37 \\
\hline 2 & $16 / 03-19 / 04$ & 148 & 37 & $16 / 03-19 / 04$ & 148 & 37 \\
\hline 3 & 19/04-26/05 & 6 & 39 & $19 / 04-21 / 09$ & 253 & 155 \\
\hline 4 & $26 / 05-30 / 06$ & 16 & 35 & $21 / 09-24 / 10$ & 95 & 33 \\
\hline 5 & $30 / 06-08 / 09$ & 162 & 70 & ${ }^{(3)}$ & - & - \\
\hline 6 & 08/09-09/10 & 146 & 32 & - & - & - \\
\hline \multirow[t]{2}{*}{7} & 09/10-14/11 & 101 & 36 & _ & - & - \\
\hline & \multicolumn{6}{|c|}{$2000 / 2001$} \\
\hline 1 & $14 / 11-18 / 12$ & 316 & 34 & $24 / 10-27 / 11$ & 227 & 34 \\
\hline 2 & $18 / 12-24 / 01$ & 176 & 37 & $27 / 11-08 / 01$ & 248 & 40 \\
\hline 3 & $24 / 01-05 / 03$ & 203 & 40 & $08 / 01-14 / 02$ & 287 & 37 \\
\hline 4 & 05/03-09/04 & 247 & 40 & $14 / 02-26 / 03$ & 216 & 40 \\
\hline 5 & 09/04-14/05 & 37 & 35 & $26 / 03-07 / 05$ & 54 & 42 \\
\hline 6 & $14 / 05-25 / 06$ & 43 & 42 & $07 / 05-09 / 11$ & 337 & 186 \\
\hline 7 & $25 / 06-30 / 08$ & 54 & 66 & - & - & - \\
\hline 8 & $30 / 08-08 / 10$ & 162 & 39 & - & - & - \\
\hline 9 & $08 / 10-13 / 11$ & 86 & 36 & - & - & - \\
\hline
\end{tabular}

${ }^{(1)}$ Precipitação pluvial. ${ }^{(2)}$ Corte de uniformização. ${ }^{(3)}$ Não houve desenvolvimento da planta. 
A não-produção de forragem, mesmo com aplicação de água por irrigação, está associada a temperaturas abaixo de $15^{\circ} \mathrm{C}$, e a períodos de dias curtos (fotoperíodo), que impedem o desenvolvimento das gramíneas forrageiras tropicais (Magalhães, 1985).

Em relação ao início do ciclo reprodutivo das espécies forrageiras (emissão de panículas ou florescimento), época em que há uma interrupção do crescimento vegetal, as plantas apresentaram o seguinte comportamento: capim-pojuca, $80 \%$ de florescimento na segunda quinzena de março; capim-braquiária e capim-marandu, ocorrência no final de abril; capim-tanzânia, ocorrência a partir da segunda quinzena de maio; capim-elefante e capim-coastcross ocorrência nos meses de junho e julho. O capim-pojuca foi o primeiro a iniciar o período reprodutivo, indicando maior sensibilidade às condições climáticas de entressafra, como baixas temperaturas e período de dias curtos. Tais condições fizeram com que a relação de produção de forragem de entressafra e safra dessa espécie fosse de $39 \%$, enquanto nas demais, essa relação foi maior que $55 \%$.

A irrigação propiciou maiores rendimentos de forragem e a melhor resposta foi do capim-elefante, seguido pelo capim-tanzânia (Tabela 3). Relacionando-se a produção das forrageiras à irrigação no período de entressafra, com a produção da safra, verifica-se que houve um acúmulo médio de forragem nessa época, de aproximadamente $50 \%$ do acúmulo da safra. Esse resultado é semelhante aos de Alvim et al. (1986) em Coronel Pacheco, MG, e aos de Benedetti et al. (2000) em Uberlândia, MG, cujos trabalhos foram realizados nas mesmas condições climáticas deste.

Tabela 3. Matéria seca $\left(t \mathrm{tha}^{-1}\right)$ de forrageiras em relação à irrigação, no Município de São Carlos, $\mathrm{SP}^{(1)}$.

\begin{tabular}{lcc}
\hline Tratamento & Irrigado & Não irrigado \\
\hline Capim-elefante & $46,1 \mathrm{a}$ & $28,2 \mathrm{~b}$ \\
Capim-tanzânia & $29,2 \mathrm{~b}$ & $18,4 \mathrm{~cd}$ \\
Capim-pojuca & $23,6 \mathrm{c}$ & $18,1 \mathrm{~cd}$ \\
Capim-braquiária & $24,3 \mathrm{c}$ & $16,1 \mathrm{cde}$ \\
Capim-marandu & $23,6 \mathrm{c}$ & $15,4 \mathrm{cde}$ \\
Capim-coastcross & $16,1 \mathrm{de}$ & $12,7 \mathrm{e}$ \\
\hline Média & $27,2 \mathrm{~A}$ & $18,2 \mathrm{~B}$ \\
Entressafra/safra $(\%)$ & 54,3 & 30,7 \\
\hline
\end{tabular}

${ }^{(1)}$ Médias seguidas da mesma letra não diferem entre si pelo teste de Tukey a $5 \%$ de probabilidade.

\section{Conclusões}

1. Em São Carlos, região central do Estado de São Paulo, a estacionalidade de produção de pastagens irrigadas é de 65 a 70 dias, durante o período de 25 de junho a 10 de setembro.

2. As forrageiras capim-elefante e capim-tanzânia apresentam maior resposta à aplicação complementar de água por irrigação.

\section{Referências}

AlVIM, M.J.; BOTREL, M.A.; NOVELLY, P.E. Produção de gramíneas tropicais e temperadas, irrigadas na época da seca. Revista da Sociedade Brasileira de Zootecnia, v.15, p.384-392, 1986.

BEnEDetTI, E.; DEMETRIO, R.A.; COlmAnetTI, A.L. Avaliação da resposta da cultivar Tanzânia (Panicum maximum) irrigada em solo de cerrado brasileiro. In: CONGRESSO PANAMERICANO DE LECHE, 7., 2000, Havana. Anais. Havana: Fepale, 2000. p.27-29.

BRASIL. Ministério da Agricultura e Reforma Agrária. Secretaria Nacional de Irrigação. Normais climatológicas: 1961-1990. Brasília: Departamento Nacional de Meteorologia, 1992. 84p.

CORSI, M. Manejo de plantas forrageiras de gênero Panicum. In: SIMPÓSIO SOBRE MANEJO DA PASTAGEM, 9., 1988, Piracicaba. Anais. ed. rev. Piracicaba: Fealq, 1995. p.17-36.

FARIA, V.D.; CORSI, M. Atualização em produção de forragem. Piracicaba: Fealq, 1986. 76p.

GUELFI FILHO, H. Efeito da irrigação sobre a produtividade do capim-elefante (Pennisetum purpureum) variedade napier. 1972. 128p. Dissertação (Mestrado) - Escola Superior de Agricultura Luiz de Queiroz, Piracicaba.

GUELFI FILHO, H. Efeito da irrigação sobre o capim colonião (Panicum maximum). Revista O Solo, v.68, p.12-16, 1978.

HILLESHEIM, A. Manejo do gênero Pennisetum sob pastejo. In: SIMPÓSIO SOBRE MANEJO DA PASTAGEM, 9., Piracicaba, 1988. Anais. ed. rev. Piracicaba: Fealq, 1995. p.37-68.

KALMBACHER, R.S.; MULLAHEY, J.J.; MARTIN, F.G.; KRETSCHMER, A.E. Effect of clipping on yield and nutritive value of "Suerte" Paspalum atratum. Agronomy Journal, v.89, p.476481, 1997.

MAGALHÃES, A.C.N. Fotossíntese. In: FERRI, M.G. (Ed.). Fisiologia vegetal. 2.ed. São Paulo: EPU, 1985. p.117-166.

MARASCHIN, G.E. Manejo de plantas forrageiras do gênero Digitaria, Cynodon e Chloris. In: SIMPÓSIO SOBRE MANEJO DA PASTAGEM, 9., 1988, Piracicaba. Anais. ed. rev. Piracicaba: Fealq, 1995. p.69-100.

PEIXOTO, A.M.; MOURA, J.C.; FARIA, V.P. Plantas forrageiras de pastagens. Piracicaba: Fealq, 1995. 318p. 
PENATI, M.A.; MAYA, F.L.A.; CORSI, M.; BALSADORE, M.A.A.; SANTOS, P.M.; PAGOTTO, D.; BARIONI, L.G.; MARTHA JUNIOR, G. Resposta da taxa de lotação animal em pastagem irrigada de capim tanzânia manejada em três níveis de massa de forragem pós-pastejo. In: REUNIÃO ANUAL DA SOCIEDADE BRASILEIRA DE ZOOTECNIA, 38., 2001, Piracicaba. Anais. Piracicaba: SBZ, 2001. p.346-348.

PRIMAVESI, O.; PRIMAVESI, A.C.P.A.; PEDROSO, A.F.; CAMARGO, A.C.; RASSINI, J.B.; ROCHA FILHO, J.; OLIVEIRA, G.P.; CORRÊA, L.A.; ARMELIN, M.I.A.; VIEIRA, S.R.; DECHEN, S.C.F. Microbacia hidrográfica do ribeirão Canchim: um modelo real de laboratório ambiental. São Carlos: Embrapa-CPPSE, 1999. 133p. (Boletim de Pesquisa, 5).
RASSINI, J.B. Irrigação de pastagens: freqüência e quantidade de aplicação de água em Latossolos de textura média. São Carlos: Embrapa-CPPSE, 2002. 7p. (Circular Técnica, 31).

ROLIM, F.A. Estacionalidade de produção de forrageiras. In: PEIXOTO, A.M.; MOURA, J.C.; FARIA, V.P. (Ed.). Pastagens: fundamentos da exploração racional. Piracicaba: Fealq, 1994. p.533566.

SAS INSTITUTE (Cary, Estados Unidos). SAS/STAT User's guide: statistics, version 6, 4th ed. Cary, 1993. 1686p.

ZIMMER, A.H.; EUCLIDES, V.P.B.; MACEDO, M.C.M. Manejo de plantas forrageiras do gênero Brachiaria. In: SIMPÓSIO SOBRE MANEJO DA PASTAGEM, 9., 1988, Piracicaba. Anais. ed. rev. Piracicaba: Fealq, 1995. p.101-104.

Recebido em 2 de junho de 2003 e aprovado em 11 de maio de 2004 